\title{
Educating Health Professionals about Disability: A Review of Interventions
}

\section{Tom Shakespeare ${ }^{1}$ \& Ira Kleine ${ }^{2}$}

'University of East Anglia Medical School, UK

${ }^{2}$ UCL Medical School, UK

\section{Corresponding author:}

Tom Shakespeare, Medical School, University of East Anglia, Earlham Road, Norwich, UK

Email: tom.shakespeare@uea.ac.uk, Phone: +44 (0) 1603 591952

\begin{abstract}
Health professionals need to understand the human rights and health needs of disabled people. This review of evidence on interventions demonstrates that a range of often innovative approaches have been trialled. Lectures by faculty are less effective in changing attitudes than contact with disabled people themselves. Existing examples of good practice need to be scaled up, and better and more long-term evaluations of impact are required.
\end{abstract}

Keywords: disability, human rights, attitudes, students

\section{Background}

Disability is a social issue, not just a medical one (Shakespeare 2006). But people with disabilities have health needs arising from their primary impairment as well as general health needs (Shakespeare 2012) and sometimes a narrower margin of health (World Health Organization and World Bank 2011). People with disabilities often do feel healthy and can be successful in managing their own health needs if they receive the appropriate support and information (Watson 2002, Nazli 2012). Yet evidence shows that these health needs are not adequately met, due to financial access and attitudinal barriers. Analysis of the World Health Survey showed that people with disabilities were twice as likely to find health care provider skills and equipment inadequate to meet their needs; three times as likely to be denied care; and four times as likely to be treated badly by health care providers (World Health Organization and World Bank 2011). This evidence is reinforced by other 
studies (Aulagnier et al. 2005, Dorji \& Solomon 2009, Cervasio 2010, Pace et al. 2011). Analysis of the 2006 US Medical Expenditure Panel Survey revealed that people with disabilities were more likely than nondisabled people to think that their doctor had not listened to them, treated them with respect, taken enough time, involved them in treatment decisions or explained treatments properly (Smith 2009). In the UK, the Formal Investigation into Inequalities in Health found that people with mental illness and people with intellectual impairments received a worse service from health professionals, which may have contributed to the poorer outcomes they experienced (Disability Rights Commission 2006).

Given evidence of discomfort, negative attitudes and lack of knowledge on the part of health professionals, there is a need to ensure better training and education about disability (Larson-McNeal et al. 2002, Eddey \& Robey 2005, Chmar et al. 2007, Shakespeare et al. 2009, Baker 2011, lezzoni \& Long-Bellil 2012, Wilkinson et al. 2012, ). Ensuring this is a legal obligation for countries that have ratified the Convention on the Rights of Persons with Disabilities (UN 2006), Article 25 (d) states that States Parties shall:

Require health professionals to provide care of the same quality to persons with disabilities as to others, including on the basis of free and informed consent by, inter alia, raising awareness of the human rights, dignity, autonomy and needs of persons with disabilities through training and the promulgation of ethical standards for public and private health care.

Bearing this legal standard in mind, the following competencies could be proposed, drawing on Kirschner \& Curry (2009):

1. Framing disability within the context of human diversity across the lifespan and within social and cultural environments.

2. Skills training for assessment of disability and functional consequences of health conditions, considering implications for treatment and management.

3. Training in general principles concerning etiquette for interactions with persons with disabilities.

4. Learning about roles of other health care professionals forming integrated teams to care for persons with disabilities.

5. 5 Understanding the legal framework of national anti-discrimination legislation, the Convention on the Rights of Persons with Disabilities, relevant ethical standards, and the principles of reasonable accommodation and universal design.

6. Competency in patient-centred care approaches, including patients' perception of quality of life.

Despite efforts to improve professional education on disability, to date there has been no comprehensive overview. The purpose of this paper is to review what has been trialled and, where known, the outcomes of these trials.

\section{Methodology}

Electronic database searches were conducted with MedLine, which produced 1666 possible publications. Titles were scanned and abstracts read, to ascertain relevance. Inclusion criteria: relevance to any aspect of: attitudes of health care workers (students or professionals) towards people with any form of disability; teaching methods used to educate students or professionals about disability; disability curriculum content; or integration of disability teaching into existing curricula. Exclusion criteria: articles that dealt solely with clinical issues and papers solely concerned with improving teaching of rehabilitation sciences.

\section{Results}

The search produced 192 relevant articles; 106 of these could be accessed online and downloaded as full texts. 48 of these papers concerned a specific, relevant teaching intervention or evaluation, of which five related to in-service training and the remainder to pre-qualification training.

\section{Geographical spread}

The search was limited to studies in English or French. 28 papers described interventions in the USA, 12 in the UK, three in Australia and one each in France, Germany, Hong Kong, New Zealand, South Africa, Sweden, and Switzerland.

\section{Different approaches}

A variety of approaches to improving attitudes, knowledge and practice have been trialled, often in combination. Starting with the distinction that Symons et al. (2009) make between school-based education, community-based experiences, and clinical experiences, we created a classification based on an inductive analysis (see Figure 1). Typical examples are discussed in the following sections, and the results table (see Table 1) summarizes all the included studies. 


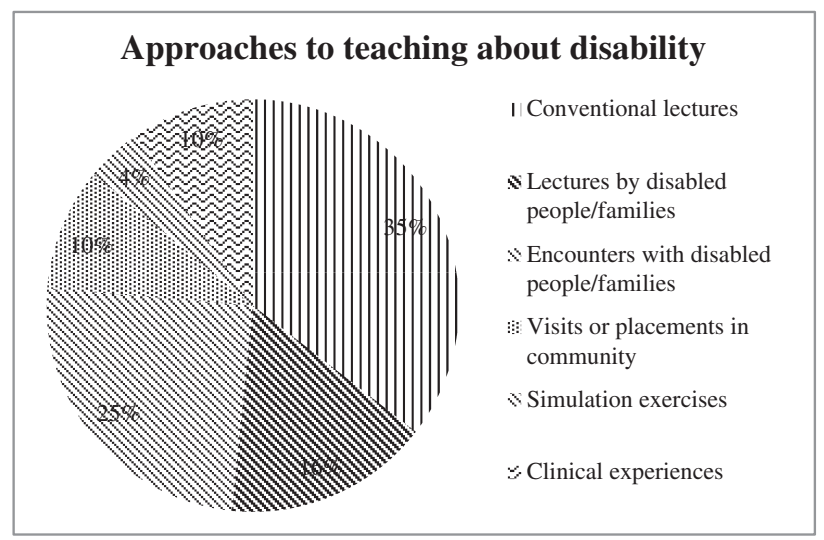

Figure 1 Approaches to teaching about disability.

\section{Conventional lecture or seminar delivered by faculty staff (33 papers)}

Teaching on disability is very common. While any training is good, having a few hours teaching about disability is likely to be insufficient to change attitudes, instill required knowledge or develop skills (Richard et al. 2005, Delucia \& Davis 2009). Rather than simply relying on didactic instruction, experiential learning with reflective components is recommended for training dental students about care of people with intellectual disabilities (Delucia \& Davis 2009). Innovative approaches using computer-based training were reportedly effective (Ruiz et al. 2006, Kleinert et al. 2007) and can be easier to deliver; for example an interactive module featuring a deaf-blind virtual patient (Sanders et al. 2008).

\section{Teaching delivered by disabled people or their family members (15 papers)}

Hearing from those with direct experience of disability is likely to make more impact and be more memorable. For example, Monash University medical students engaged with tutors with intellectual disabilities on a three-hour communication workshop, which increased their understanding and comfort levels with this traditionally underserved community (Tracy \& lacono 2008). At Leeds University, a series of seminars for medical students on 'valuing diversity' were taught, inter alia, by deaf people, disabled people from the local Centre for Integrated Living, people with mental health conditions and people with intellectual disabilities (Thistlethwaite \& Ewart 2003).

\section{Encounters with patients, advocates or standardized patients (23 papers)}

Research with dental students shows that prior experience with people with intellectual disabilities is associated with comfort levels in treating this population (Delucia \& Davis 2009). Supervised contact has been found to have more impact on knowledge and attitudes than lectures alone, for example in improving confidence in working with people with intellectual disabilities (Adler et al. 2005). Home visits are typical (Sharma et al. 2006, Mullen et al. 2010), and various approaches have been successfully trialled, including inter-professional learning (Street et al. 2007, Anderson et al. 2010). In a more elaborate US project, family medicine clerkship students conducted a series of interviews with standardized patient educators with disabilities that were videoed and discussed in feedback sessions (Duggan et al. 2009). Innovative senior mentoring programmes in South Carolina involved students being paired with an older person to do assignments ranging from clinical assessments to home safety assessments (Corwin et al. 2006).

One-off events are another option. In North Staffordshire, the production of a Toolkit to improve health services for people with intellectual disability (ID) (available at www.keele.ac.uk/depts/ns/ toolkitpeopleld) was followed by a workshop, partly led by people with ID themselves (Read \& Rushton 2012). A US college of medicine organized a panel of senior citizens to interact with medical students (Tandon et al. 2011). Before offering vision screening to Special Olympic athletes with ID, 71.5\% of volunteer optometry students and professionals lacked confidence; after a day of training and at least two days' contact, nearly $80 \%$ were confident or very confident at examining this population (Adler et al. 2005).

Virtual engagement has also been attempted. St Bartholemew School of Nursing and Midwifery (London, UK) experimented with an online discussion forum which involved mental health service users educating mental health nursing students in the context of Enquiry-Based Learning (Simpson et al. 2008). Service users were supported 


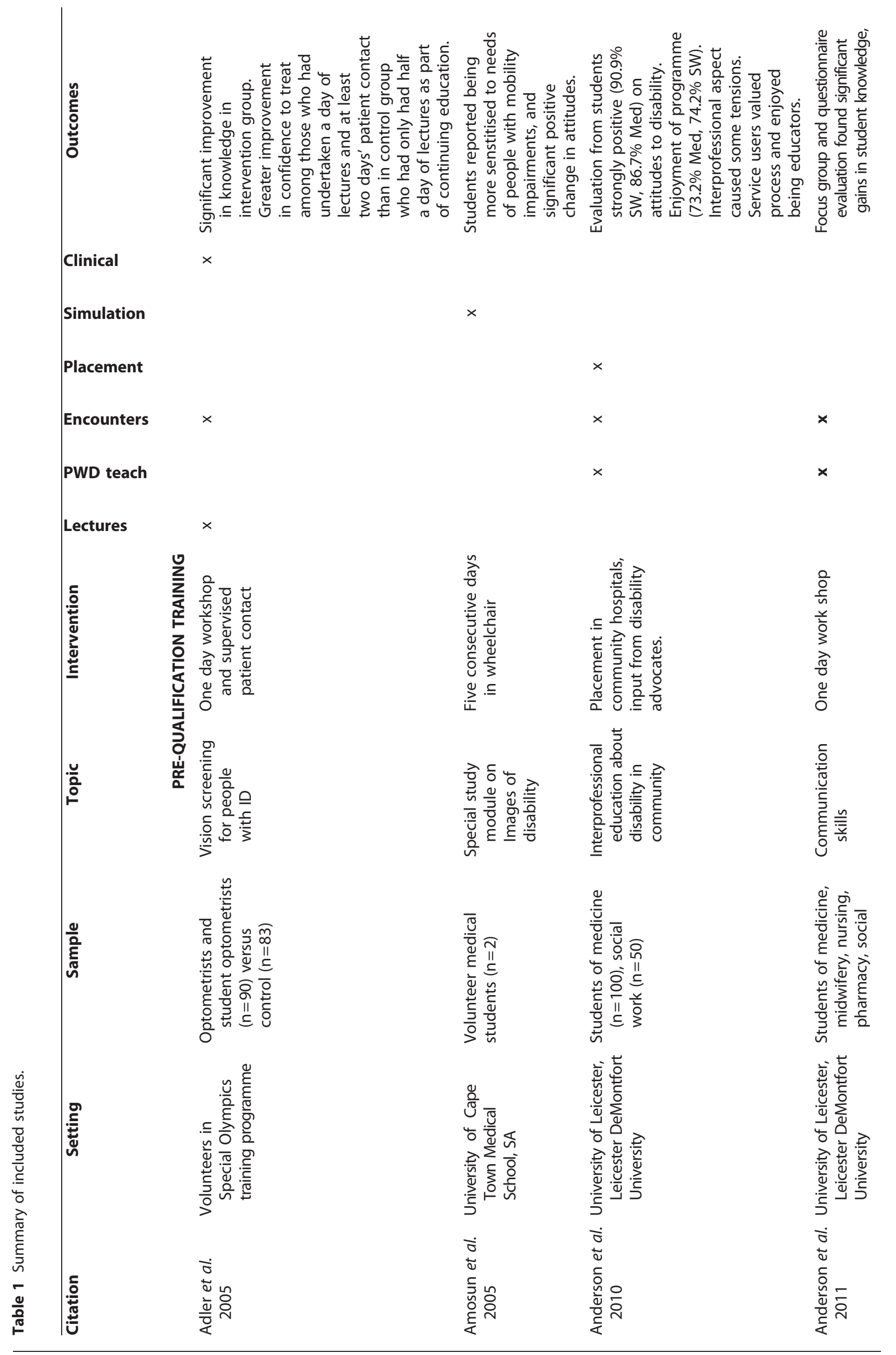




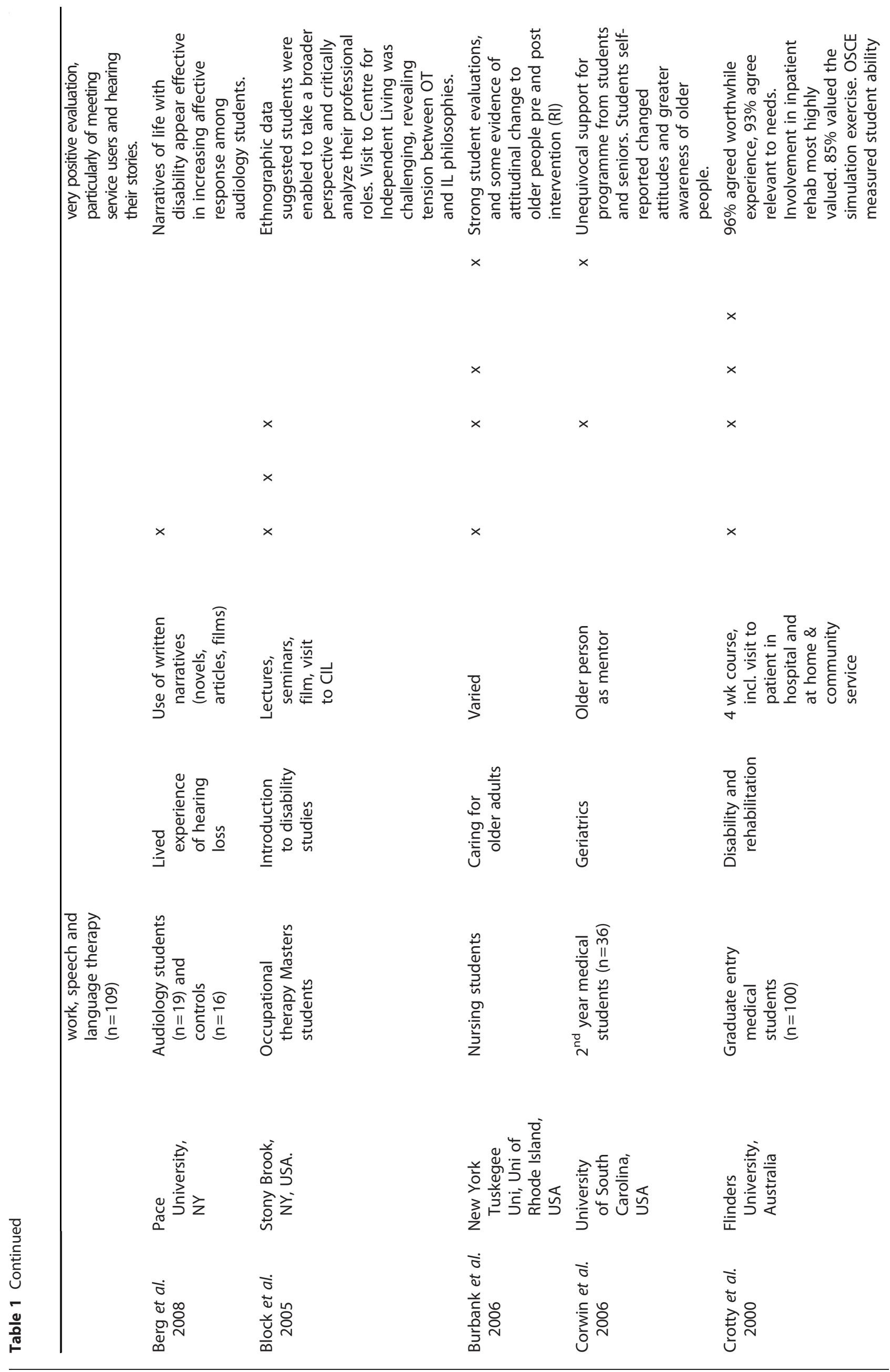




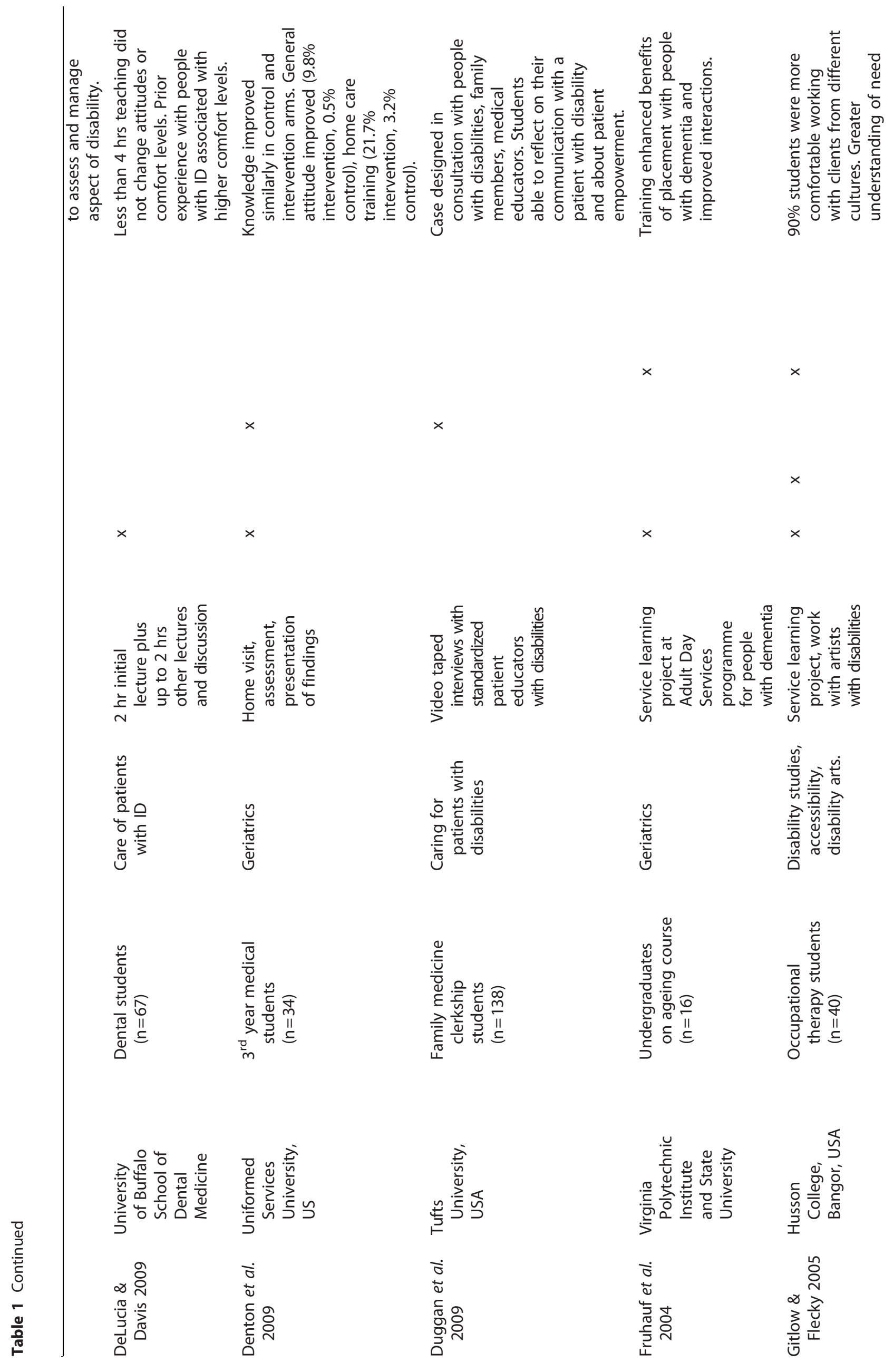




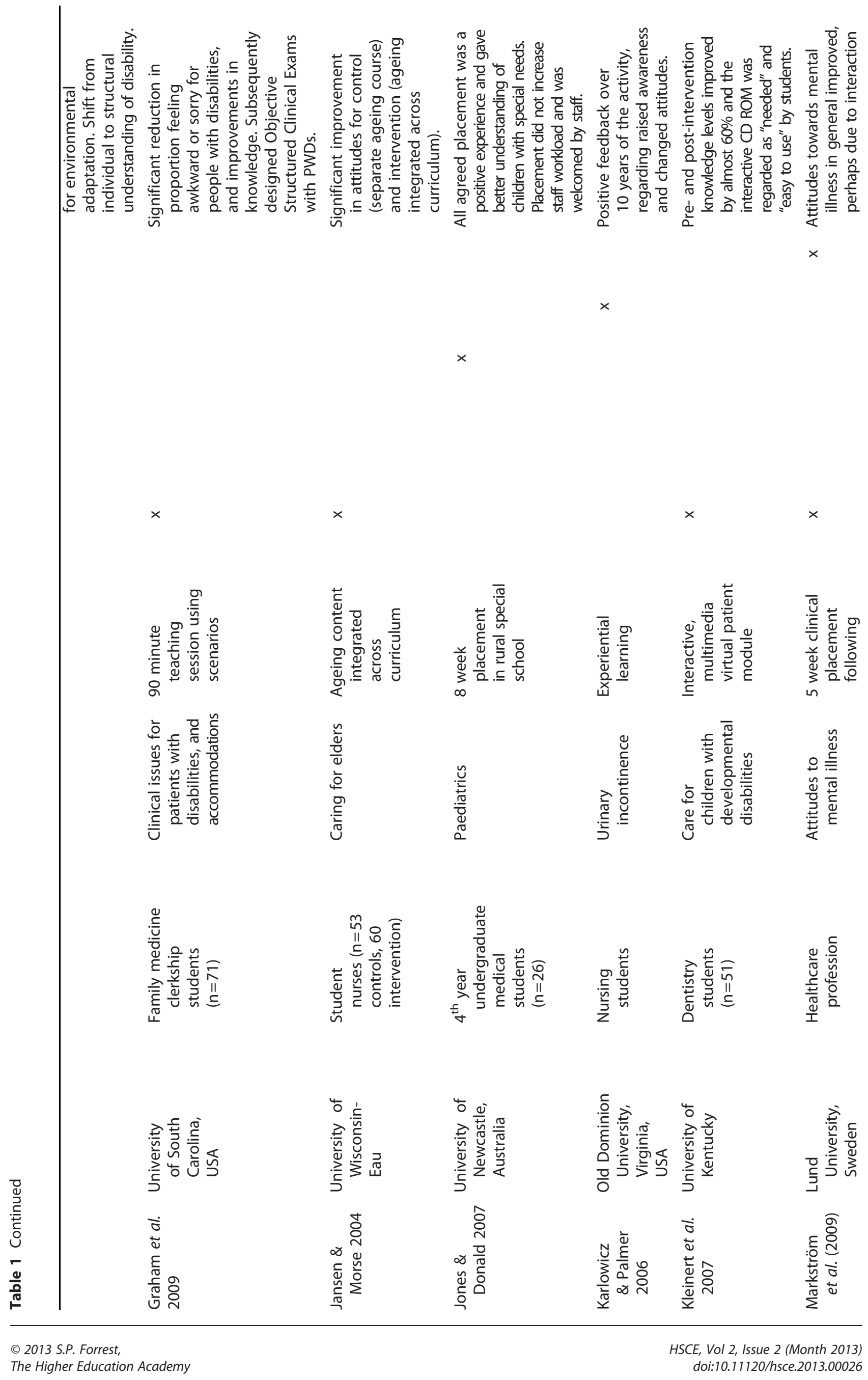




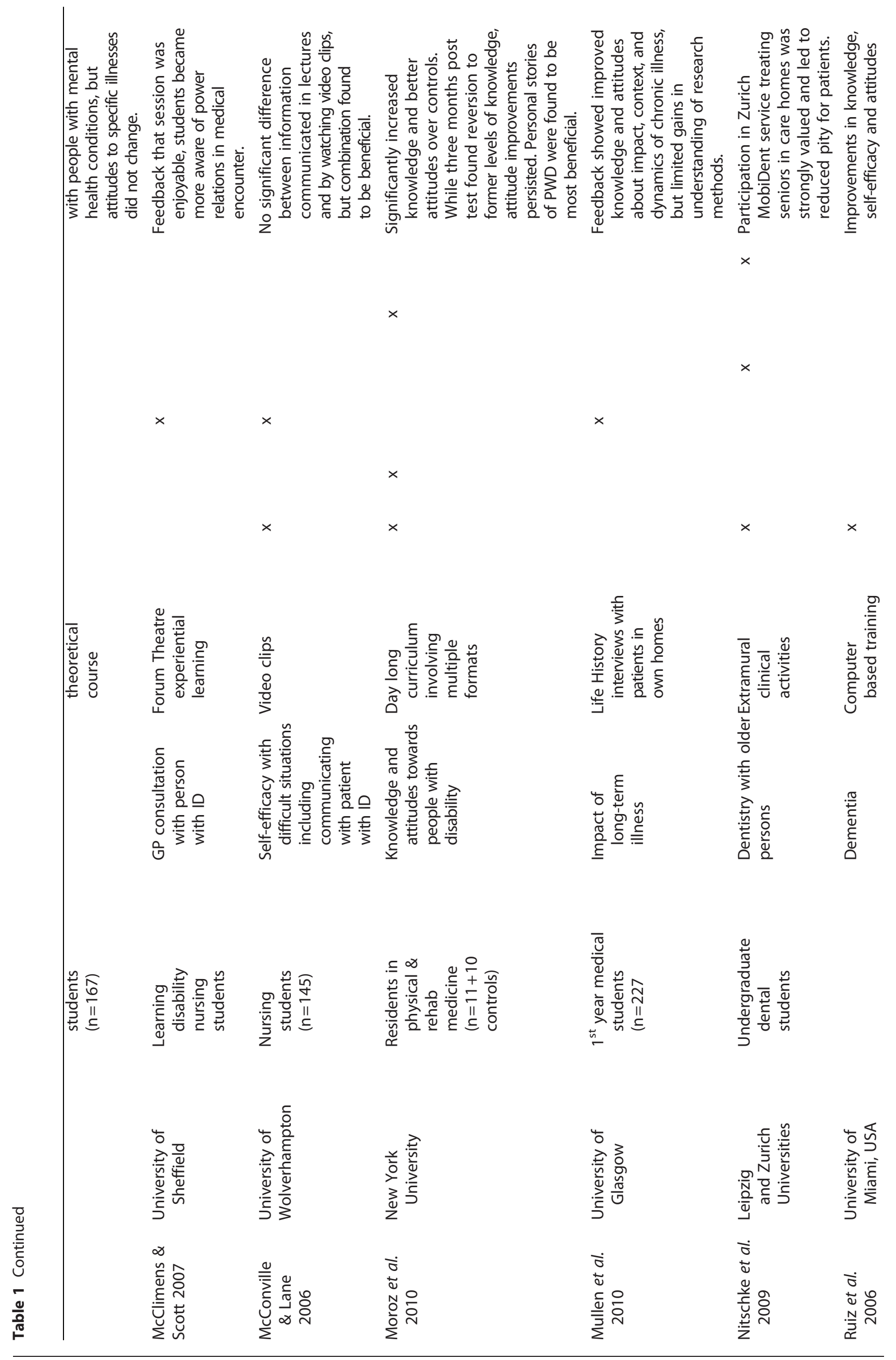




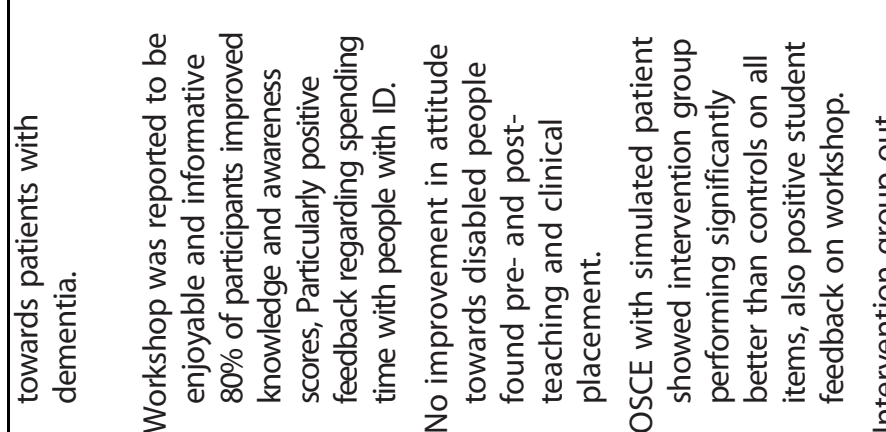

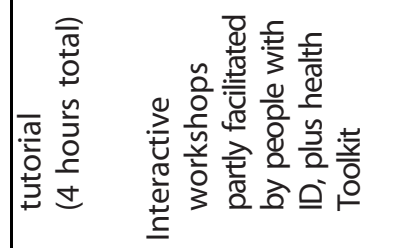

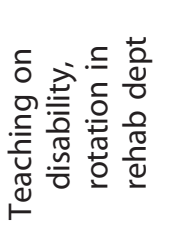

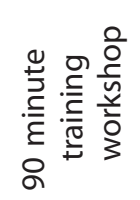

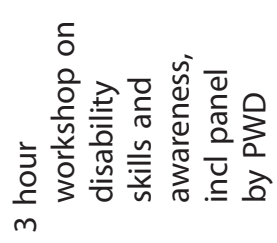

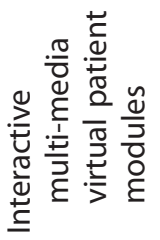

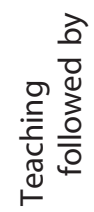

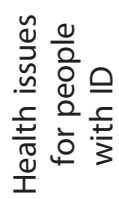

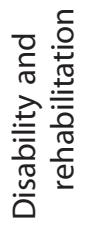

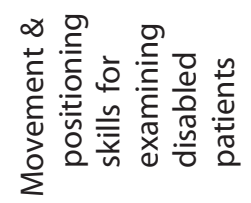

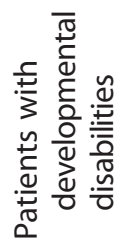

$\frac{\vec{t}}{\overline{0}}$
$\frac{0}{0}$
$\frac{n}{0}$

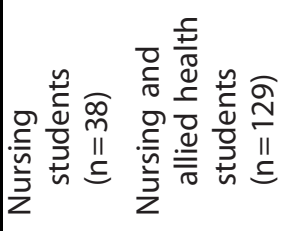
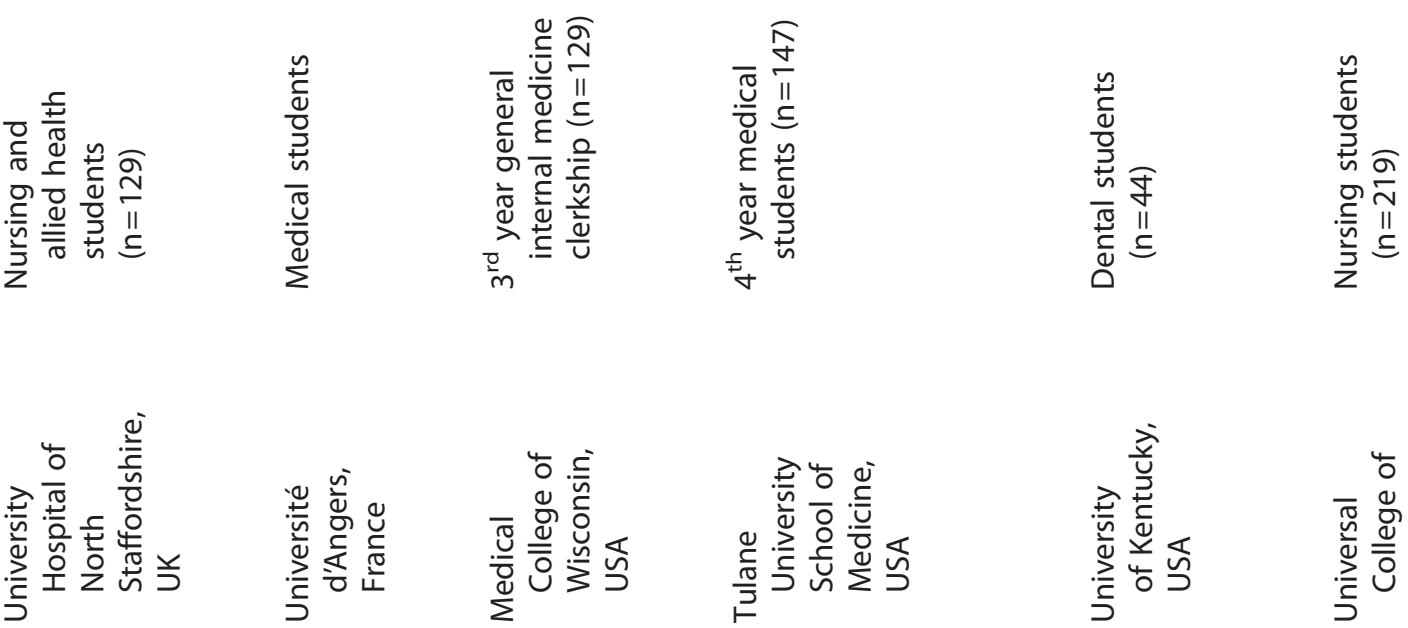

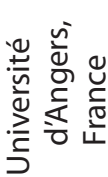

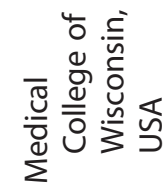

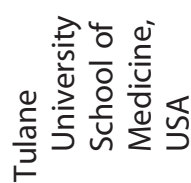

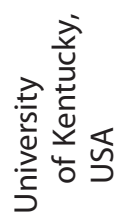

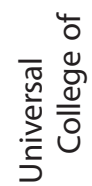

๖

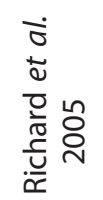

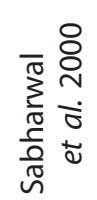

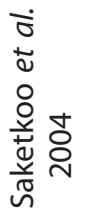

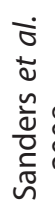

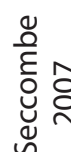




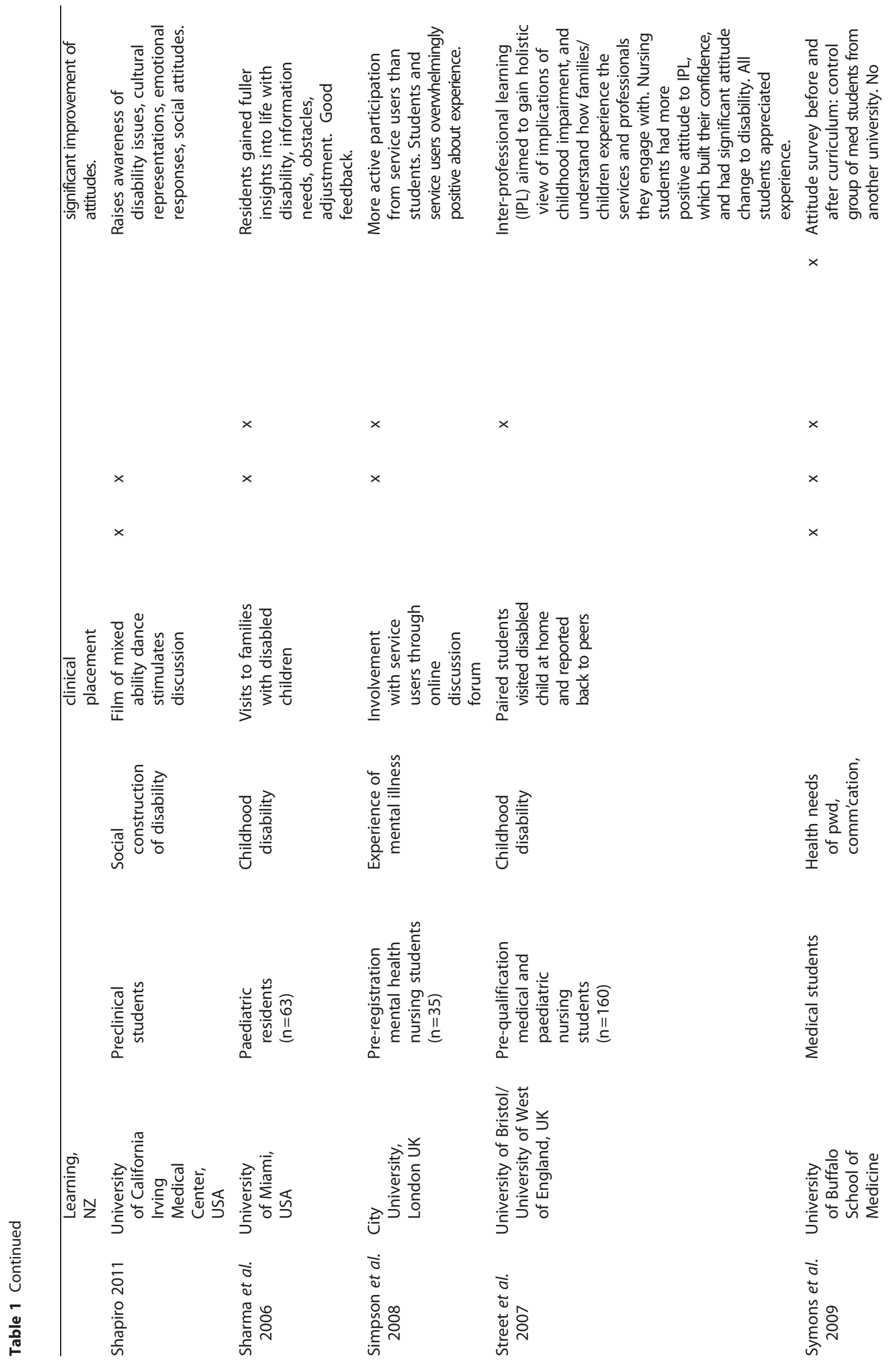




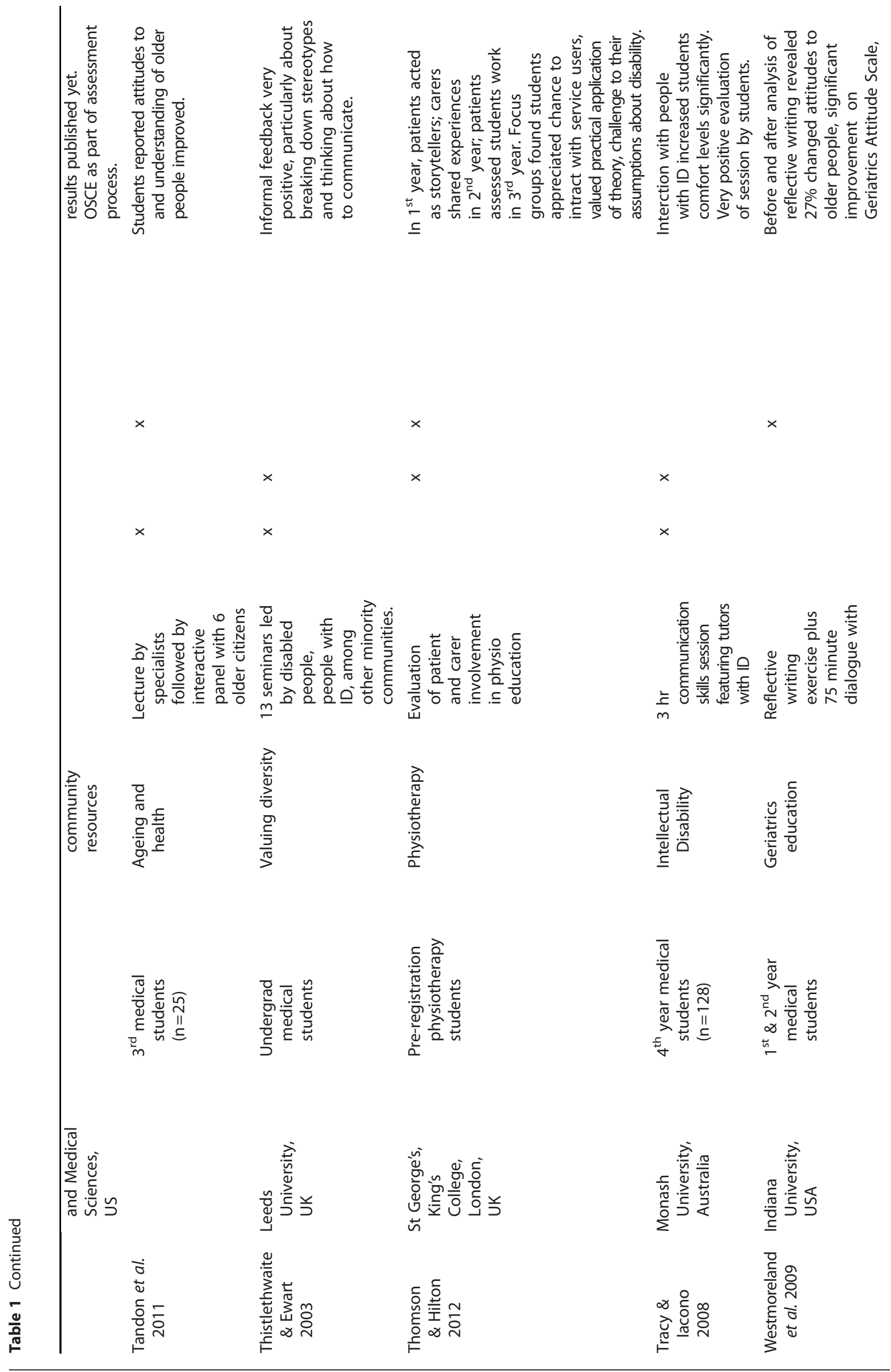




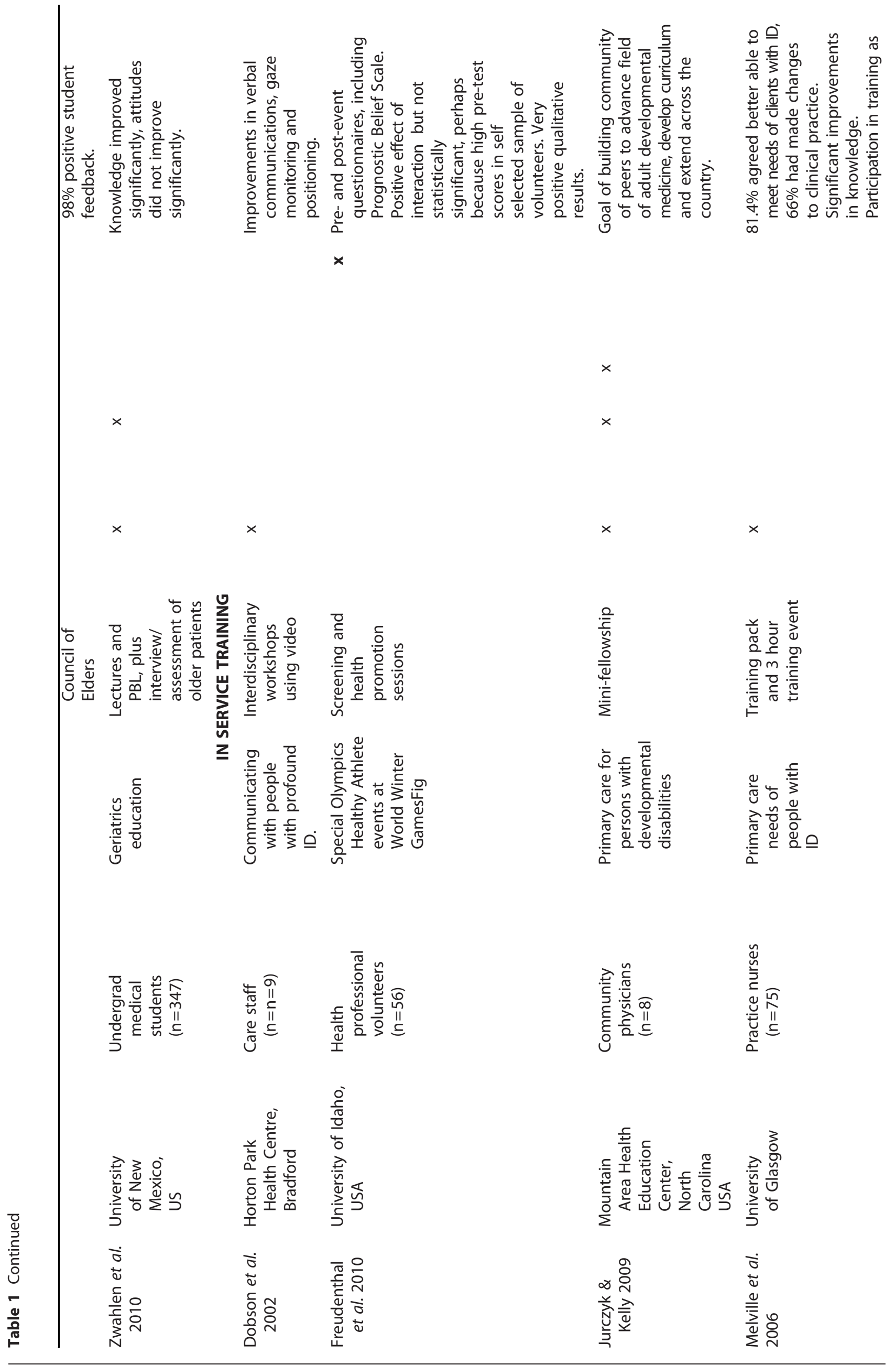




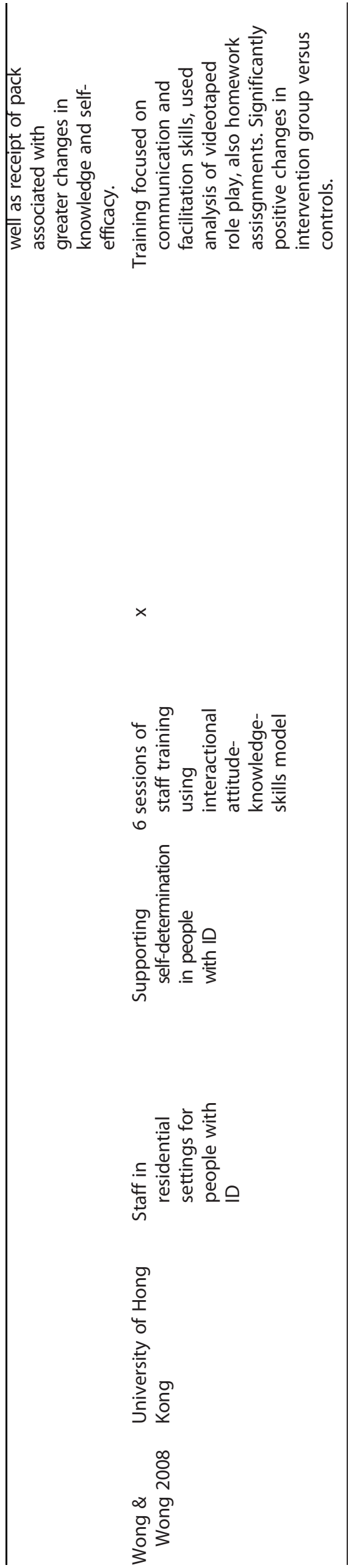

engage with students online and paid a small honorarium. All students and service users interviewed were overwhelmingly positive about the experience.

\section{Placements or visits with community facilities and organizations (nine papers)}

Service learning is an experiential learning approach where students learn by doing (Gitlow \& Flecky 2005). Prior training can enhance the benefits of placement in community facilities, for example with older adults with dementia (Fruhauf et al. 2004), and thus improve learning of interaction skills. An Australian study where medical students spent eight weeks on placement in rural special schools led to better understanding of children with special needs (Jones \& Donald 2007). In Leicester, medical students and social workers had four-week placements in community hospitals, together with training delivered by a Centre for Integrated Living (Anderson et al. 2010).

\section{Simulation exercises (four papers)}

A traditional way of changing attitudes is via simulation exercises - for example, spending time in a wheelchair or wearing spectacles that simulate sight loss (Crotty et al. 2000, Amosun et al. 2005) or wearing incontinence undergarments to engender empathy (Karlowicz \& Palmer 2006). The goals are to develop interpersonal skills, increase empathy and educate about practical issues, such as accessibility (Crotty et al. 2000). While these experiences seem to be highly valued by participants, there is a risk of seeing disability in individualistic terms. If the main problems of disabled people result from poverty, prejudice and discrimination, then sitting in a wheelchair for half a day is unlikely to result in a full understanding, and may even distort perceptions.

\section{Clinical experience (nine papers)}

Symons et al. (2009) argue for the importance of introducing students to caring for patients with disabilities early in their career, and ensuring that disability is integrated throughout the curriculum and at every stage. They suggest that the skills acquired through caring for patients with disabilities are transferrable to other patient care and foster general professionalism. Markström et al. (2009) found that five-week clinical placements for students in healthcare professions reduced stigma associated with mental illness. Swiss dental students who were able to treat older people reported feeling less pity and frustration than German students, who could observe problems but not help (Nitschke et al. 2009). 


\section{Continuing education}

In-service training has also been successfully trialled. For example, practice nurses in Scotland were trained in the primary healthcare needs of people with intellectual disabilities (Melville et al. 2006) with concrete outcomes. Interdisciplinary experiential training workshops delivered to care staff at a day centre for people with intellectual disabilities improved their communication and interaction with clients (Dobson et al. 2002).

\section{Teaching modalities}

Inter-professional education appears particularly appropriate for learning about disability, given that disabled people often engage with a multiplicity of different professionals (Anderson et al. 2010). Bringing together social work students with medical students, or nursing students with medical students, or a range of health professional students, has been effective (Street et al. 2007, Markström et al. 2009, Anderson et al. 2010, Anderson et al. 2011).

Innovative curricula drawing on the humanities have potential to illuminate and broaden the professional's understanding of disability (Evans 2002, Kaptein \& Lyons 2009). For example, an intervention using narratives of hearing loss enabled audiology students to think beyond technical issues and improved their listening skills (Berg et al. 2008). Other interventions have drawn on reflective writing (Westmoreland et al. 2009), cinema (Block et al. 2005) and performance (Kahtan et al. 1994, McClimens \& Scott 2007, Shapiro 2011).

\section{Outcomes of interventions}

Impact of these interventions was generally assessed by pre- and post-intervention attitudinal change, tests of knowledge, and/or by student feedback (consistently positive, e.g. Crotty et al. (2000) found $96 \%$ positive feedback). There is a need for an updated instrument for measuring healthcare professional attitude (Lam et al. 2010).

Across the included studies, significant improvement in knowledge was common, although this sometimes tailed off over time. However, it was sometimes harder to detect improvements in attitudes when the sole intervention was traditional teaching (Richard et al. 2005, Seccombe 2007, Zwahlen et al. 2010).

Across the studies, the most positive evaluations were of opportunities to meet disabled or older people, associated with positive change in attitudes (Gitlow \& Flecky 2005, Denton et al. 2009, Moroz et al. 2010, Anderson et al. 2011, Read \& Rushton 2012), even when only conducted online (Simpson et al. 2008). Spending time in clinical settings (Markström et al. 2009) is also positively valued, but does not necessarily lead to attitudinal change (Richard et al. 2005, Seccombe 2007).

If students are to take disability seriously, it needs to be part of their assessment. Good practice is to use Standardized Patient Clinical Cases (Saketkoo et al. 2004) or Objective Standardized Clinical Encounters (Crotty et al. 2000, Sabharwal et al. 2000, Symons et al. 2009) to assess student learning, with disabled people being trained as standardized patients.

The best measure of effectiveness would be patientreported satisfaction with health professionals who had undergone a particular form of training. Such longitudinal impact evaluations appear to be absent from the literature.

\section{Discussion}

There are many different ways of teaching students about disability, and the included papers often do not give a clear impression of the content and philosophy underlying the interventions. Medical educators themselves may need to examine their own attitudes and understandings (Gitlow \& Flecky 2005), particularly tutors who are responsible for guiding clinical education.

Achieving a holistic understanding requires meeting healthy disabled and older people and learning from them. Half of the interventions did involve direct contact in a non-clinical setting. However, only $16 \%$ of the interventions studied in this paper entailed the disabled person acting as an expert, teaching the students. The greatest learning seems to come when students are encouraged to critically reflect on their experiences (Crotty et al. 2000, Duggan et al. 2009), including their emotional reactions to disability. One-off interventions or lectures are less effective than immersive workshops or combinations of activities. The 'spiral of learning' approach, where a range of strategies are used across different years of the medical school curriculum, reinforcing learning points, seems likely to deliver the best outcomes (Corwin et al. 2006, Symons et al. 2009), particularly given that disability is complex and multi-faceted.

Obstacles to improving teaching about disability include clinical overload (Dehaitem et al. 2008) and time pressures. Elaborate initiatives may be demanding in terms of preparation and/or delivery (Anderson et al. 2010, Corwin et al. 2006, which raises sustainability questions (Burbank et al. 2006). Innovation in disability teaching may rely on one member of the education team having the necessary knowledge and enthusiasm.

This review included nearly 50 papers describing more than 90 different teaching and learning activities. While we cannot say definitively what 
works best to improve health professional knowledge and attitudes in the area of disability, it seems clear that learning from success and widespread adoption of good practice is required, if the ambitions of the Convention on the Rights of Persons with Disabilities are to be achieved.

\section{Note}

Tom Shakespeare was responsible for the study design, analysis and writing up of this paper. Ira
Kleine conducted literature research and reviewed the paper. The review was conducted whilst Tom Shakespeare was a staff member at the World Health Organization and Ira Kleine was an intern at the World Health Organization. The authors alone are responsible for the views expressed in this paper, and they do not necessarily represent the decisions or policies of the World Health Organization. Thanks to John Spencer for comments on the paper.

\section{References}

-Adler, P., Cregg, M., Duignan, A., llett, G. and Woodhouse, J.M. (2005) Effect of training on attitudes and expertise of optometrists towards people with intellectual disabilities. Ophthalmic Physiol Opt. 25 (2), 105-18.

-Albrecht, G.L. and Devlieger, P.J. (1999) The disability paradox: high quality of life against all odds. Social Science and Medicine 48 (8), 977-88.

-Amosun, S.L., Volmink, L. and Rosin, R. (2005) Perceived images of disability: the reflections of two undergraduate medical students in a university in South Africa on life in a wheelchair. Disability and Rehabilitation 27 (16), 961-966.

-Amundson, R. (2010) Quality of life, disability, and hedonic psychology. Journal for the Theory of Social Behaviour 40 (4), 374-392.

-Anderson, E.S., Smith, R. and Thorpe, L.N. (2010) Learning from lives together: medical and social work students' experiences of learning from people with disabilities in the community. Health Soc Care Community 18 (3), 229-240.

-Anderson, E.S., Ford, J. and Thorpe, L. (2011) Learning to listen: improving students' communication with disabled people. Med Teach 33 (1), 44-52.

-Aulagnier, M., Verger, P., Ravaud, J.-F., Souville, M., Lussault, P.-Y., Garnier, J.-P. and Paraponaris, A. (2005) General practitioners' attitudes towards patients with disabilities: the need for training and support. Disabil Rehabil 27 (22), 1343-1352.

-Baker, M.J. (2011) Education requirements for nurses working with people with complex neurological conditions: relatives' perceptions. Nurse Educ Pract 11 (4), 268-272.

-Berg, A.L., Canellas, M., Salbod, S. and Velayo, R. (2008) Exposure to disability and hearing loss narratives in undergraduate audiology curriculum. Am J Audiol. 17 (2), 123-8.

Block, P., Ricafrente-Biazon, M., Russo, A., Chu, K.Y., Sud, S., Koerner, L., Vittoria, K., Landgrover, A. and Olowu, T. (2005) Introducing disability studies to occupational therapy students. Am J Occup Ther 59 (5), 554-560.

-Burbank, P.M., Dowling-Castronovo, A., Crowther, M.R. and Capezuti, E.A. (2006) Improving knowledge and attitudes toward older adults through innovative educational strategies. J Prof Nurs 22 (2), 91-97.

Cervasio, K. (2010) Systematic literature review of nursing students and nurses attitudes toward children with disabilities. Journal of Health Sciences \& Practice 1 (9), 1-16.

$\checkmark$ Chmar, J.E., Harlow, A.H., Weaver, R.G. and Valachovic, R.W. (2007) Annual ADEA survey of dental school seniors, 2006 graduating class. J Dent Educ 71 (9), 1228-53

Corwin, S.J., Frahm, K., Ochs, L.A., Rheaume, C.E., Roberts, E. and Eleazer, G.P. (2006) Medical student and senior participants' perceptions of a mentoring program designed to enhance geriatric medical education. Gerontol Geriatr Educ 26 (3), 47-65.

-Crotty, M., Finucane, P. and Ahern, M. (2000) Teaching medical students about disability and rehabilitation: methods and student feedback. Med Educ. 34 (8), 659-64.

-Dehaitem, M.J., Ridley, K., Kerschbaum, W.E. and Inglehart, M.R. (2008) Dental hygiene education about patients with special needs: a survey of U.S. programs. J Dent Educ 72, 1010-1019.

-Delucia, L.M. and Davis, E.L. (2009) Dental students' attitudes toward the care of individuals with intellectual disabilities: relationship between instruction and experience. J Dent Educ 73 (4), 445-453. 
-Denton, G.D., Rodriguez, R., Hemmer, P.A., Harder, J., Short, P. and Hanson, J.L. (2009) A prospective controlled trial of the influence of a geriatrics home visit program on medical student knowledge, skills, and attitudes towards care of the elderly. J Gen Intern Med. 24 (5), 599-605.

\section{Disability Rights Commission (2006) Equal} Treatment: closing the gap: a formal investigation into physical health inequalities experienced by people with learning disabilities and/or mental health problems. London: Commission, Disability Rights.

Dobson, S., Upadhyaya, S. and Stanley, B. (2002) Using an interdisciplinary approach to training to develop the quality of communication with adults with profound learning disabilities by care staff. Int J Lang Commun Disord 37, 41-57.

Dorji, S. and Solomon, P. (2009) Attitudes of health professionals towards persons with disabilities in Bhutan. Asia Pacific Disability Rehabilitation Journal 20 (2), 32-42.

Duggan, A., Bradshaw, Y.S., Carroll, S.E., Rattigan, S.H. and Altman, W. (2009) What can I learn from this interaction? A qualitative analysis of medical student self-reflection and learning in a standardized patient exercise about disability. $J$ Health Commun 14, 797-811.

Eddey, G.E. and Robey, K.L. (2005) Considering the culture of disability in cultural competence education. Acad Med 80, 706-712.

-Evans, M. (2002) Reflections on the humanities in medical education. Med Educ 36, 508-513.

Freudenthal, J.J., Boyd, L.D. and Tivis, R. (2010) Assessing change in health professions volunteers' perceptions after participating in Special Olympics healthy athlete events. J Dent Educ 74, 970-979.

-Fruhauf, C.A., Jarrott, S.E. and Lambert-Shute, J.J. (2004) Service-learners at dementia care programs: an intervention for improving contact, comfort, and attitudes. Gerontol Geriatr Educ 25, 37-52.

Gibson, J., Lin, X., Clark, K., Fish, H., and Phillips, M. (2010) Teaching medical students rehabilitation medicine. Disability and Rehabilitation 32 (23), 1948-1954.

Gitlow, L. and Flecky, K. (2005) Integrating disability studies concepts into occupational therapy education using service learning. Am J Occup Ther 59, 546-553.

Graham, C.L., Brown, R.S., Zhen, H. and McDermott, S. (2009) Teaching medical students about disability in family medicine. Fam Med 41, 542-544.

Gutenbrunner, C., Schiller, J., Schwarze, M., Fischer, V., Paulmann, V., Haller, H. and Küther, G. (2010) Hannover model for the implementation of physical and rehabilitation medicine teaching in undergraduate medical training. J Rehabil Med 42 (3), 206-213.

-lezzoni, L.I. and Long-Bellil, L.M. (2012) Training physicians about caring for persons with disabilities: "Nothing about us without us!". Journal of Disability and Health 5 (3), 136-139.

-Jansen, D.A. and Morse, W.A. (2004) Positively influencing student nurse attitudes toward caring for elders: results of a curriculum assessment study. Gerontol Geriatr Educ 25, 1-14.

Jones, P. and Donald, M. (2007) Teaching medical students about children with disabilities in a rural setting in a school. BMC Med Educ 7 (12).

-Jurczyk, I. and Kelly, R.B. (2009) Embedding developmental disabilities into medical training. N C Med J 70, 556-560.

-Kahtan, S., Inman, C., Haines, A. and Holland, P. (1994) Teaching disability and rehabilitation to medical students. Med Educ 28, 386-93.

Kaptein, A.A. and Lyons, A.C. (2009) The doctor, the breath and Thomas Bernhard: using novels in health psychology. J Health Psychol 14, 161-170.

-Karlowicz, K.A. and Palmer, K.L. (2006) Engendering student empathy for disabled clients with urinary incontinence through experiential learning. Urol Nurs 26, 373-378.

Kirschner, K.L. and Curry, R.H. (2009) Educating health care professionals to care for patients with disabilities. JAMA 302, 1334-1335.

Kleinert, H.L., Sanders, C., Mink, J., Nash, D., Johnson, J., Boyd, S. and Challman, S. (2007) Improving student dentist competencies and perception of difficulty in delivering care to children with developmental disabilities using a virtual patient module. J Dent Educ 71, 279-286.

Lam, W.Y., Gunukula, S.K., McGuigan, D., Isaiah, N., Symons, A.B. and Akl, E.A. (2010) Validated instruments used to measure attitudes of healthcare students and professionals towards patients with physical disability: a systematic review. J Neuroeng Rehabil 7, 55.

Larson-McNeal, M., Carrothers, L.A. and Premo, B. (2002) Providing primary health care for people with physical disabilities: a survey of California physicians. Pomona, CA: Center for Disability Issues and the Health Professions, Western University of Health Sciences.

-Markström, U., Gyllensten, A.L., Bejerholm, U., Björkman, T., Brunt, D., Hansson, L., Leufstadius, C., Sandlund, M., Svensson, B., Ostman, M., and Eklund, M. (2009) Attitudes towards mental illness among health care students at Swedish universities - a 
follow-up study after completed clinical placement. Nurse Educ Today 29, 660-665.

-McClimens, A. and Scott, R. (2007) Lights, camera, education! The potentials of forum theatre in a learning disability nursing program. Nurse Educ Today 27, 203-209.

-McConville, S.A. and Lane, A.M. (2006) Using on-line video clips to enhance self-efficacy toward dealing with difficult situations among nursing students. Nurse Educ Today 26, 200-208.

Melville, C.A., Cooper, S.-A., Morrison, J., Finlayson, J., Allan, L., Robinson, N., Burns, E. and Martin, G. (2006) The outcome of an intervention study to reduce the barriers experienced by people with intellectual disabilities accessing primary health care services. Journal of Intellectual Disability Research $\mathbf{5 0}$ (1), 11-17.

-Moroz, A., Gonzalez-Ramos, G., Festinger, T., Langer, K., Zefferino, S. and Kalet, A. (2010) Immediate and follow-up effects of a brief disability curriculum on disability knowledge and attitudes of PM\&R residents: a comparison group trial. Med Teach 32 (8), e360-364.

Mullen, K., Nicolson, M. and Cotton, P. (2010) Improving medical students' attitudes towards the chronic sick: a role for social science research. $B M C$ Med Educ 10 (84).

-Nazli, A. (2012) "I'm healthy": construction of health in disability. Disability and Health Journal 5, 233-240.

- Nitschke, I., Reiber, T. and Sobotta, B.A.J. (2009) Undergraduate teaching in gerodontology in Leipzig and Zürich - a comparison of different approaches. Gerodontology 26, 172-178.

Oliver, M. (1990) The politics of disablement. Basingstoke: Macmillan.

-Pace, J.E., Shin, M. and Rasmussen, S.A. (2011) Understanding physicians' attitudes toward people with Down syndrome. Am J Med Genet A. 155A (6), 1258-63.

Read, S. and Rushton, A. (2012) Cultivating understanding of health issues for adults with intellectual disability. Nurse education today. Available at http://www.ncbi.nlm.nih.gov/pubmed/ 22520238 (accessed 09 July 2013).

-Richard, I., Compain, V., Mouillie, J.M., Adès, F., Garnier, F., Dubas, F. and Saint-André, J.P. (2005) Evaluation of the attitude towards disabled persons of $3 r d$ and 4 th year medical students using the "Attitude towards disabled persons" questionnaire. Effect of courses and rotations in physical medicine and rehabilitation departments. Ann Readapt Med Phys 48, 662-667.
Ruiz, J.G., Smith, M., van Zuilen, M.H., Williams, C. and Mintzer, M.J. (2006) The educational impact of a computer-based training tutorial on dementia in long term care for licensed practice nursing students. Gerontol Geriatr Educ 26, 67-79.

- Sabharwal, S., Sebastian, J.L. and Lanouette, M. (2000) An educational intervention to teach medical students about examining disabled patients. JAMA 284, 1080-1081.

-Saketkoo, L., Anderson, D., Rice, J., Rogan, A. and Lazarus, C.J. (2004) Effects of a disability awareness and skills training workshop on senior medical students as assessed with self ratings and performance on a standardized patient case. Teach Learn Med 16, 345-354.

-Sanders, C., Kleinert, H.L., Boyd, S.E., Herren, C., Theiss, L. and Mink, J. (2008) Virtual patient instruction for dental students: can it improve dental care access for persons with special needs? Spec Care Dentist 28, 205-213.

- Seccombe, J.A. (2007) Attitudes towards disability in an undergraduate nursing curriculum: the effects of a curriculum change. Nurse Educ Today 27, 445-451.

Shakespeare, T. (2006) Disability Rights and Wrongs. London: Routledge.

- Shakespeare, T. (2012) Still a health issue. Journal of Disability and Health 5 (3), 129-131.

-Shakespeare, T., lezzoni, L.I. and Groce, N.E. (2009) Disability and the training of health professionals. The Lancet 374, 1815-1816.

-Shapiro, J. (2011) Dancing wheelchairs: an innovative way to teach medical students about disability. Am. J. Med 124, 886-887.

-Sharma, N., Lalinde, P.S. and Brosco, J.P. (2006) What do residents learn by meeting with families of children with disabilities?: a qualitative analysis of an experiential learning module. Pediatr Rehabil 9, 185-189.

-Simpson, A., Reynolds, L., Light, I. and Attenborough, J. (2008) Talking with the experts: evaluation of an online discussion forum involving mental health service users in the education of mental health nursing students. Nurse Educ Today 28, 633-640.

Smith, D.L. (2009) Disparities in patient-physician communication for persons with a disability from the 2006 Medical Expenditure Panel Survey (MEPS) Disability and Health Journal 2, 206-215.

-Street, K.N., Eaton, N., Clarke, B., Ellis, M., Young, P. M., Hunt, L. and Emond, A. (2007) Child disability case studies: an interprofessional learning opportunity for medical students and paediatric nursing students. Med Educ 41, 771-780. 
Sumilo, D., Kurinczuk, J.J., Redshaw, M.E. and Gray, R. (2012) Prevalence and impact of disability in women who had recently given birth in the UK. BMC Pregnancy and Childhood 12 (31).

Symons, A.B., McGuigan, D. and Akl, E.A. (2009) A curriculum to teach medical students to care for people with disabilities: development and initial implementation. BMC Med Educ 9 (78).

-Tandon, R., Kalra, A., Reis, J., Kirby, R. and Jokela, J.A. (2011) Changing medical students' attitudes about ageing and health. Med Educ 45, 1136-1137.

-Thistlethwaite, J.E. and Ewart, B.R. (2003) Valuing diversity: helping medical students explore their attitudes and beliefs. Med Teach 25, 277-281.

-Thomson, D. and Hilton, R. (2012) An evaluation of students' perceptions of a college-based programme that involves patients, carers and service users in physiotherapy education. Physiother Res Int 17, 36-47.

-Tracy, J. and lacono, T. (2008) People with developmental disabilities teaching medical students - does it make a difference? J Intellect Dev Disabil 33, 345-348.

-Watson, N. (2002) Well, I know this is going to sound very strange to you, but I don't see myself as a disabled person: identity and disability. Disability and Society 17 (5), 509-528.

-Westmoreland, G.R., Counsell, S.R., Sennour, Y., Schubert, C.C., Frank, K.I., Wu, J., Frankel, R.M., Litzelman, D.K., Bogdewic, S.P. and Inui, T.S. (2009) Improving medical student attitudes toward older patients through a "council of elders" and reflective writing experience. J Am Geriatr Soc 57, 315-320.

-Wilkinson, J., Dreyfus, D., Cerreto, M. and Bokhour, B. (2012) "Sometimes I feel overwhelmed": educational needs of family physicians caring for people with intellectual disability. Intellect Dev Disabil. 50 (3), 243-50.

World Health Organization (2001) International Classification of Functioning, Disability and Health. Geneva: WHO.

World Health Organization and World Bank (2011) World report on disability. Geneva: WHO.

ZZwahlen, D., Herman, C.J., Smithpeter, M.V., Mines, J. and Kalishman, S. (2010) Medical students' longitudinal and cross-sectional attitudes toward and knowledge of geriatrics at the University of New Mexico School of Medicine. J Am Geriatr Soc 58, 2049-2050. 